
\title{
$\begin{array}{ll}\text { Research Square } & \text { Preprints are preliminary reports that have not undergone peer review. } \\ \text { They should not be considered conclusive, used to inform clinical practice, } \\ \text { or referenced by the media as validated information. }\end{array}$
}

\section{Clinical Characteristics of 60 Adult Cancer Patients Experience Covid-19: A Descriptive-Analytical Study}

Mozaffar Aznab

Kermanshah University of Medical Sciences

Narges Eskandari-Roozbahani ( $\sim$ neskandari32@gmail.com )

Kermanshah University of Medical Sciences

Homa Moazen

Shahid Sadoughi University of Medical Science

\section{Research Article}

Keywords: Clinical Study, Hematologic neoplasms, COVID-19, Malignant neoplasms

Posted Date: May 13th, 2021

DOI: https://doi.org/10.21203/rs.3.rs-463503/v2

License: @ (i) This work is licensed under a Creative Commons Attribution 4.0 International License. Read Full License 


\section{Abstract \\ Background}

This study aimed to describe the clinical symptoms, the severity of the disease, and survival status of COVID-19 cancer patients, and comparing the results in the different cancer subtypes and stages among various ages/sexes and techniques of treatment.

\section{Method:}

In a descriptive-analytical study, the clinical status of 60 cancer patients with a history of Covid-19 over the past year from the covid-19 pandemic in Iran (Jan. 2020-Dec.2020) was assessed.

\section{Results}

Most of the patients (68\%) were in the solid tumor categories. The mean age of the men was $52 \pm 13$ years, and women were $47 \pm 13$ years $(P<0.05)$. Most cases of COVID-19 positive in solid tumor were breast cancer $(24.4 \%)$, colon cancer $(22 \%)$, gastric cancer (9.8\%), and in hematologic malignancy, lymphoma (31.6\%), chronic lymphocytic leukemia (CLL) (31.6\%), and acute leukemia (21.1\%). There was a statistically significant difference between two categories of cancer in the clinical manifestations; the stage of cancer and survival status $(P<0.05)$.

\section{Conclusion}

Based on our results risk factors for Covid-19 disease progression, severe pulmonary involvement, and fatal complications in patients with malignancy require further evaluation based on tumor type, stage, age, sex, and treatment options.

\section{Introduction}

One of the strategies in the control of morbidity of disease is to characterize the high-risk groups. In this way, supportive proceedings apply to prevent the prevalence of the disease. Since COVID-19 commenced to spread to the world, different symptoms and various disease courses have been reported in this regard. Among all literature published during the pandemic, this fact was clarified that there are high-risk groups in the morbidity and mortality of COVID-19. Some who were male ( $v s$ female); older; with comorbidities, such as hypertension, diabetes, obesity, chronic liver disease, cardiovascular and respiratory disorders; and cancer patients were regarded as high-risk groups [23].

A cancer patient is a general epithet while this group of patients encompasses a diversity of tumor subtypes, stages, age, treatment options, dissimilar prognosis, and sequels. Despite some suggestions for managing cancer patients, including instructions in the ESMO site [7], nonetheless, COVID-19 is controversial among oncologist specialists.

In this study, we aimed to describe the clinical symptoms, the severity of the disease, and survival status of COVID-19 cancer patients who were referred to our clinic during the COVID-19 pandemic in Iran (Jan. 2019- Dec. 2019). Besides, we compared our results in the different cancer subtypes and stages among various ages/sexes and techniques of treatment.

\section{Subjects And Method}


Approval was obtained from the ethics committee of Kermanshah university of medical science. The procedures used in this study adhere to the tenets of the Declaration of Helsinki.

During a year of the prevalence of covid-19 in Iran from June.2020 to the end of Dec. 2020, all cancer patients who were referred to our clinic and were under chemotherapy and/or target therapy were followed-up. A total of 60 patients during this year experienced COVID-19. All clinical information about these patients were extracted, and the primary outcomes were recorded in a specific form. Different information, including clinical manifestations, hematological reports, treatment options, the diagnostic method of disease, survival status, and severity of the disease were recorded under different cancer subtypes and stages. We analyzed the effect of tumor features (subgroups and stages), and demographic information (age and sex) on clinical manifestations, survival status, therapeutic outcomes, and severity of disease COVID-19 in two categories cancer.

In order to analyze the data, descriptive indicators, including frequency, percentage, mean and standard deviation (SD) was applied and independent t-test, Mann-Whitney $\mathrm{U}$, Chi-square, and Fisher tests were used, as well. SPSS 22 statistical software was used for data analysis and the significance level was considered $<0.05$.

\section{Results}

During one year, 60 cancer patients who had experienced Covid-19 disease were evaluated for symptoms. Most of the patients (60\%) were infected with CVID-19 in the last three months of the study. While in the first trimester of the pandemic, the number of patients with Covid-19 was only 7, due to the observance of hygienic principles and adherence to self-care education [1].

Patients included 27 men (45\%), 33 women (55\%) with a mean age of $51.1 \pm 13.8$ years (range 24 to 77 years). There was no statistically significant difference in the prevalence of the disease between the two sexes. The mean age of the men was $52 \pm 13$ years, and women were $47 \pm 13$ years. There was a statistically significant difference in the age of infection between males and females $(P<0.05)$.

In terms of cancer type, patients were divided into two categories: patients with hematologic malignancy (including lymphoma, leukemia, myeloma, and Hodgkin) and patients with solid tumor (including the brain, breast, gastrointestinal tract, larynx, lung, ovary, pancreas, prostate, and skin cancers). Among all patients, $68 \%$ were in the solid tumor categories and $32 \%$ in the hematologic categories. In order of number, most cases of COVID-19 positive in solid tumor were breast cancer (24.4\%), colon cancer (22\%), gastric cancer (9.8\%), lung cancer (7.3\%), and ovarian cancer (7.3\%). About hematological malignancy, most cases were observed in lymphoma (31.6\%), chronic lymphocytic leukemia (CLL) (31.6\%), and acute leukemia (21.1\%) (Table 1). There was no statistically significant difference between the two categories in terms of age and gender.

The most clinical manifestations (70 - 60\%) of COVID-19 were fever, tiredness, exhaustion, and dry cough. Other symptoms such as aches and pains, sore throat, headache, difficulty breathing or shortness of breath, and frailty (severe weakness) were observed in $40-55 \%$ of cases.

Less common symptoms (<30\%) were diarrhea, conjunctivitis, ageusia (loss of taste) and anosmia (loss of smell), dysarthria (difficulty speaking), confusion, and bewilderment (Table 2). The clinical manifestations of solid and hematological cancers are listed in Table 2 . There was a statistically significant difference between the two groups in the incidence of frailty $(P=0.029)$ and dysarthria $(P=0.009)$ symptoms. Patients with solid tumor experienced the dysarthria $(26 \%)$ and frailty more than patients with hematologic cancer.

About the blood findings and pulse oximetry results of patients, the percentage of saturated oxygen (SO2\%) before oxygen therapy was in the range of $76-96 \%$, and after oxygen therapy was $80-96 \%$. According to the paired t-test, there 
was a significant difference between the mean of $\mathrm{SO}_{2}$ before and after treatment: 83.81 vs. $89.31(\mathrm{P}<0.001)$. But there was no statistically significant difference between the two cancer groups (Table 3 ).

Other blood factors are listed in Table 3. Among hematologic factors, there was a statistically significant difference between the two groups only in the mean platelet count $(P=0.044)$.

Reverse transcription-polymerase chain reaction (RT-PCR) was the main laboratory technique in diagnosis Covid-19, in $33.3 \%$ of patients despite the symptoms, RT-PCR was negative. The relationship between cancer type and the RT-PCR test result was not significant.

In terms of pulmonary involvement in the computerized tomography (CT) scan report, $50.3 \%$ of patients had pulmonary involvement, of which $16.7 \%$ had unilateral involvement, $22 \%$ bilateral, and $8.3 \%$ had pleural involvement combined with unilateral or bilateral pulmonary involvement. There was no statistically significant difference between two groups in terms of pulmonary involvement parameters.

Patients were treated with chemotherapy based on the type of cancer (Table 4), and when they get Covid-19, the proposed therapies were used to control the disease. Overall, $40 \%$ of patients used single-dose or combination medications of ReciGen (interferon beta-1a) (36.7\%), Remdesivir (21.7\%), corticosteroids (2\%), and Hydroxychloroquine (8.3\%), and others used other medications or supportive proceedings to control the disease.

There was no significant relationship between the treatment options and the type of cancer.

A total of $68.3 \%$ of patients with severe symptoms were admitted to the intensive care unit (ICU), of which $13.3 \%$ needed a ventilator. There was no statistically significant relationship between the type of cancer and hospitalized in the ICU and the need for a ventilator.

In solid tumor, $9.8 \%$ and in hematological malignancy $15.8 \%$ of patients died. There was no statistically significant relationship between cancer type and patients' survival status.

Among various types of cancer, only patients who were stage IV died of Covid-19 and in the other stages, there was no death report. There was a statistically significant difference between the stage of cancer and survival status $(P=0.043)$.

A total of 7 deaths were reported, of which 4 were related to solid tumor (two cases of lung cancer, one case of the brain, and one case of cholangiocarcinoma) and three cases were related to hematological malignancy (myeloma and refractory acute leukemia).

There were no statistically significant differences between hematologic and solid cancers in terms of survival, but there was a statistically significant difference between hematologic malignancy and life status (Table 5). The deceased patients had no comorbidity except cancer. All patients had a dry cough, but none had conjunctivitis, confusion, and bewilderment. The PCR test was positive in all patients and all required a ventilator. The deceased solid tumor patients had symptoms of fever, shortness of breath, chest pain, and frailty. Diarrhea was common in the deceased hematologic cancer patients, but none had pain, sore throat, ageusia and anosmia, dysarthria, or frailty.

\section{Discussion}

From the beginning of the coronavirus pandemic in Iran (January 2020), all patients undergoing chemotherapy and/or target therapy referred to our clinic were trained in disease control and prevention. Over the course of a year, 60 cancer patients experienced Covid-19 disease. As patients with different types of cancer have different phenotypes and vulnerabilities in COVID-19 [11], patients were divided into two categories: solid tumor and hematologic malignancy, and various aspects of COVID-19 symptoms in these two patient groups were assessed separately. Most patients were female 
and their age was lower than males. Prior studies have displayed that cancer patients are more likely to develop COVID-19 and its severe form than people who do not have cancer $[8,13]$.

The mean age of Covid-19 in our cancer patients was $51.1 \pm 13.8$, which was lower than the mean age of previous studies. A systematic review of risk factors for mortality among 1169 patients with hematologic malignancy with experience with Covid-19 revealed that age $>60$ years is a risk factor for mortality in these patients [20]. Similar results have been reported in other studies that contradict the results of our study [22].

In accordance with $\mathrm{Ma}$ Ja et al findings [14], in our study, most patients with Covid-19 were from the solid tumor group and most cases were observed in patients with breast and colon cancer.

In contrast to our findings, in a nationwide cohort study conducted in the Netherlands, the results of Covid-19 in 442 registered patients revealed that patients with hematologic malignancy or lung cancer were at higher risk for a worse COVID-19 outcome [6]. In some other previous studies, lung cancer has been reported as the most common cancer associated with Covid-19 disease $[5,26,27]$.

In addition to the usual symptoms of Covid-19 disease, which include a dry cough, fever, and fatigue, there are also symptoms associated with the involvement of certain organs of the body, such as respiratory symptoms (cough, shortness of breath, sore throat, rhinorrhea, hemoptysis, and chest pain) due to pulmonary involvement; gastrointestinal symptoms (diarrhea, nausea, and vomiting) due to gastrointestinal involvement; physical pain due to skeletal muscle involvement and neurological symptoms (headache, confusion, ageusia, anosmia, dysarthria, confusion, and bewilderment) due to involvement of the nervous system $[4,10]$. The most clinical manifestations of our patients, as in previous reports of cancer patients with Covid-19 [25], were fever, dry cough, and fatigue. Only in terms of dysarthria and frailty, differences were observed between the two groups of hematological and solid tumor. Besides common symptoms, the patients presented neurological symptoms such as headache, inactivity, dysarthria, confusion, bewilderment, anosmia, and ageusia. Many reports point to these neurological conditions in patients with COVID-19 [15, 16, 24]. There are several reasons for these neurological manifestations, a case report of dysarthria in a 72-year-old woman, showed a deficiency of 25- $\mathrm{OH}$ vitamin $\mathrm{D}$, parathyroid hormone, and blood calcium [3]. Other causes of neurological manifestations due to viral infections include increased levels of interleukin-6 and its subsequent infiltration of the blood-brain barrier, which has been associated with cognitive and neurodegenerative disorders [12].

In our study, $11 \%$ of patients who were infected with Covid-19 died, but there was no statistically significant difference in the mortality rate between hematologic and solid tumor groups.

In a prospective cohort study, out of 1,044 patients with cancer, $30 \%$ died. In this study, the risk factor for mortality was mentioned in elderly patients and hematologic malignancy undergoing chemotherapy [11]. Studies have suggested that the prognosis of COVID-19 patients with two or more comorbidities is not pleasant [21], while patients who died of Covid19 in our study had no underlying disease other than cancer.

In deceased hematologic cancer patients, there was a decrease in the total platelet count. Platelet depletion was a blood factor that was significantly reduced in the hematological group versus the solid tumor group. Previous research has revealed that platelets play an important role in the immune system and even have antiviral effects, so in hematologic malignancy that thrombocytopenia is usual, patients are associated with an immunodeficiency that exacerbates their disease [18].

Since the outbreak of the covid-19 epidemic, no reliable treatment has been definitively provided to reduce the course and improve the complications of the disease. The proposed treatments were based on clinical trials but did not produce the desired results. 
The treatments offered in our clinic for cancer patients with Covid-19 are performed according to the results of clinical trials and valid guidelines [7]. As these guidelines have been updated, treatment methods have changed as well. However, the use of several common Covid-19 treatment options, namely Recigen, Remdesivir, Hydroxychloroquine, and Corticosteroids, failed to control the devastating effects of the disease in patients who died.

Among the 7 patients who died, 3 were in the advanced stage of the disease (stage IV) and two patients (AML and ALL) were in the refractory group. The disease status of these patients puts them at risk of death due to their extreme vulnerability to disease progression, common and unusual infections. Therefore, the cause of death alone cannot be attributed to Covid 19. In our study, none of the patients with stage I, II, or III have died. None of the patients with chronic leukemia and lymphoma have died, as well. The risk factors that determine the progression of the disease in Covid-19 disease, severe pulmonary involvement, and more severe and fatal complications among patients with malignancy need further evaluation.

However, to reduce the risk of solid tumor patients in epidemic conditions, it is better for these patients not to develop neutropenia and to use Granulocyte Colony Stimulating Factor (G-CSFs) at the appropriate time [2, 19].

In the category of patients with hematologic malignancy, patients with acute leukemia need more attention $[1,9,17]$. Therefore, in this group, the first priority should be on prevention. Vaccination of Covid-19 in patients with acute leukemia requires further studies regarding the initiation of vaccination.

\section{Conclusion}

According to the results of statistics on deaths from cancer in our study, it is possible that cancer may not increase the risk of developing Covid-19 as much as other underlying diseases that have been reported to date. In cancer patients in the early stages of the disease, risk factors other than cancer itself should probably be considered. What is more important than the proposed treatments in controlling Covid-19 disease in cancer patients is informing patients to observe hygienic principles, promoting self-care behavior, staying in quarantine, and preventing unnecessary commute, avoiding being in places with a high risk of transmission, hand washing, wearing a mask, no stress and anxiety, training of patients' companions and caregivers and treatment staff in dealing with cancer patients, access to laboratory diagnostic equipment and continuous monitoring of hematological tests to prevent neutropenia and thrombocytopenia.

\section{Declarations}

Funding: The author(s) received no financial support for the research, authorship, and/or publication of this article.

Conflicts of interest/Competing interests: None

Ethics approval: Approval was obtained from the ethics committee of Kermanshah university of medical science. The procedures used in this study adhere to the tenets of the Declaration of Helsinki.

Consent to participate: Verbal informed consent was obtained before the interview.

Consent for publication: The participant has consented to the submission of the case report in the journal.

Availability of data and material: No additional data are available

Code availability: N/A

Authors' contributions: 
Aznab M Concepts, Design, Definition of intellectual content, Clinical studies, Manuscript preparation, Manuscript editing, Manuscript review, Data acquisition, Guarantor; Eskandari Roozbahani N Concepts, Design, Literature search, Data acquisition, Data analysis, Manuscript preparation, Manuscript editing, Manuscript review; Moazen H Literature search, Data acquisition, Statistical analysis, Manuscript preparation, Manuscript review

\section{References}

1. Aznab M. Evaluation of COVID 19 infection in 279 cancer patients treated during a 90-day period in 2020 pandemic. Int J Clin Oncol. 2020;25:1581-6.

2. Becker PS, Griffiths EA, Alwan LM, Bachiashvili K, Brown A, Cool R, Curtin P, Dinner S, Gojo I, Hicks A, Kallam A, Kidwai WZ, Kloth DD, Kraut EH, Landsburg D, Lyman GH, Miller R, Mukherjee S, Patel S, Perez LE, Poust A, Rampal R, Rosovsky R, Roy V, Rugo HS, Shayani S, Vasu S, Wadleigh M, Westbrook K, Westervelt P, Burns J, Keller J, Pluchino LA. Hematopoietic Growth Factors, Version 1.2020, Journal of the National Comprehensive Cancer Network. 18. NCCN Guidelines Insights: JNCCN; 2020. pp. 12-22.

3. Bossoni S, Chiesa L, Giustina A. Severe hypocalcemia in a thyroidectomized woman with Covid-19 infection. Endocrine. 2020;68:253-4.

4. Chen N, Zhou M, Dong X, Qu J, Gong F, Han Y, Qiu Y, Wang J, Liu Y, Wei Y. Epidemiological and clinical characteristics of 99 cases of 2019 novel coronavirus pneumonia in Wuhan, China: a descriptive study. The Lancet. 2020;395:50713.

5. China N, New Coronavirus Pneumonia Prevention and Control Protocol, in, National Health Commission of the People's Republic of China, 2020.

6. de Joode K, Dumoulin DW, Tol J, Westgeest HM, Beerepoot LV, van den Berkmortel FW, Mutsaers PG, van Diemen NG, Visser OJ. E. Oomen-de Hoop, Dutch Oncology COVID-19 consortium: Outcome of COVID-19 in patients with cancer in a nationwide cohort study. Eur J Cancer. 2020;141:171-84.

7. ESMO, CANCER PATIENT MANAGEMENT DURING THE COVID-19 PANDEMIC, (2020).

8. Ganatra S, Dani SS, Redd R, Rieger-Christ K, Patel R, Parikh R, Asnani A, Bang V, Shreyder K, Brar SS. Outcomes of COVID-19 in Patients With a History of Cancer and Comorbid Cardiovascular Disease. J Natl Compr Canc Netw. 2020;1:1-10.

9. García-Suárez J, de la Cruz J, Cedillo Á, Llamas P, Duarte R, Jiménez-Yuste V, Hernández-Rivas J, Gil-Manso R, Kwon M, Sánchez-Godoy P, Martínez-Barranco P, Colás-Lahuerta B, Herrera P, Benito-Parra L, Alegre A, Velasco A, Matilla A, Aláez-Usón MC, Martos-Martínez R, Martínez-Chamorro C, Susana-Quiroz K, Del Campo JF, de la Fuente A, Herráez R, Pascual A, Gómez E, Pérez-Oteyza J, Ruiz E, Alonso A, González-Medina J, Martín-Buitrago LN, Canales M, GonzálezGascón I, Vicente-Ayuso MC, Valenciano S, Roa MG, Monteliu PE, López-Jiménez J, Escobar CE, Ortiz-Martín J, DiezMartin JL, Martinez-Lopez J, Serí-Merino C, Queiroz-Cervantes K, Fernandez ME, Peñalva-Moreno M-J, Naya-Errea D, Bermejo-Martínez L. L. Llorente-González, H. the Asociación Madrileña de Hematología y, Impact of hematologic malignancy and type of cancer therapy on COVID-19 severity and mortality: lessons from a large population-based registry study. 13: Journal of Hematology \& Oncology; 2020. p. 133.

10. Huang C, Wang Y, Li X, Ren L, Zhao J, Hu Y, Zhang L, Fan G, Xu J, Gu X. Clinical features of patients infected with 2019 novel coronavirus in Wuhan, China, The lancet, 395 (2020) 497-506.

11. L.Y.W. Lee, J.-B. Cazier, T. Starkey, S.E.W. Briggs, R. Arnold, V. Bisht, S. Booth, N.A. Campton, V.W.T. Cheng, G. Collins, H.M. Curley, P. Earwaker, M.W. Fittall, S. Gennatas, A. Goel, S. Hartley, D.J. Hughes, D. Kerr, A.J.X. Lee, R.J. Lee, S.M. Lee, H. McKenzie, C.P. Middleton, N. Murugaesu, T. Newsom-Davis, A.C. Olsson-Brown, C. Palles, T. Powles, E.A. Protheroe, K. Purshouse, A. Sharma-Oates, S. Sivakumar, A.J. Smith, O. Topping, C.D. Turnbull, C. Várnai, A.D.M. Briggs, G. Middleton, R. Kerr, A. Gault, M. Agnieszka, A. Bedair, A. Ghaus, A. Akingboye, A. Maynard, A. Pawsey, A.A. Mohamed, A. Okines, A. Massey, A. Kwan, A. Ferreira, A. Angelakas, A. Wu, A. Tivey, A. Armstrong, A. Madhan, A. Pillai, 
A. Poon-King, B. Kurec, C. Usborne, C. Dobeson, C. Thirlwell, C. Mitchell, C. Sng, C. Scrase, C. Jingree, C. Brunner, C. Fuller, C. Griffın, C. Barrington, D. Muller, D. Ottaviani, D. Gilbert, E. Tacconi, E. Copson, E. Renninson, E. Cattell, E. Burke, F. Smith, F. Holt, G. Soosaipillai, H. Boyce, H. Shaw, H. Hollis, H. Bowyer, I. Anil, J.J. Illingworth Gibson, J. Bhosle, J. Best, J. Barrett, J. Noble, J. Sacco, J. Chacko, J. Chackathayil, K. Banfill, L. Feeney, L. Horsley, L. Cammaert, L. Mukherjee, L. Eastlake, L. Devereaux, L. Melcher, L. Cook, M. Teng, M. Hewish, M. Bhattacharyya, M. Choudhury, M. Baxter, M. Scott-Brown, M. Fittall, M. Tilby, M. Rowe, M. Agnieszka, M. Alihilali, M. Galazi, N. Yousaf, N. Chopra, N. Cox, O. Chan, O. Sheikh, P. Ramage, P. Greaves, P. Leonard, P.S. Hall, P. Naksukpaiboon, P.R. Corrie Peck, R. Sharkey, R. Bolton, R. Sargent, R. Jyothirmayi, R. Goldstein, R. Oakes, R.R. Shotton Kanani, R. Board, R. Pettengell, R. Claydon, S. Moody, S. Massalha, S. Kathirgamakarthigeyan, S. Dolly, S. Derby, S. Lowndes, S. Benafif, S. Kingdon, S. Ayers, S. Brown, S. Ellis, S. Parikh, S. Pugh, S. Shamas, S. Wyatt, S. Grumett, S. Lau, Y.N.S. Wong, S. McGrath, S. Cornthwaite, S. Eeckelaers, S. Hibbs, T. Tillet, T. Rabbi, T. Robinson, T. Roques, V. Angelis, V. Woodcock, V. Brown, Y. Peng, Y. Drew, Z. Hudson, COVID-19 prevalence and mortality in patients with cancer and the effect of primary tumour subtype and patient demographics: a prospective cohort study, The Lancet Oncology, 21 (2020) 1309-1316.

12. Li Y, Li H, Fan R, Wen B, Zhang J, Cao X, Wang C, Song Z, Li S, Li X. Coronavirus infections in the central nervous system and respiratory tract show distinct features in hospitalized children. Intervirology. 2016;59:163-9.

13. Liang W, Guan W, Chen R, Wang W, Li J, Xu K, Li C, Ai Q, Lu W, Liang H. Cancer patients in SARS-CoV-2 infection: a nationwide analysis in China. The Lancet Oncology. 2020;21:335-7.

14. Ma J, Yin J, Qian Y, Wu Y. Clinical characteristics and prognosis in cancer patients with COVID-19: A single center's retrospective study, The Journal of Infection, (2020).

15. Mao L, Jin H, Wang M, Hu Y, Chen S, He Q, Chang J, Hong C, Zhou Y, Wang D. Neurologic manifestations of hospitalized patients with coronavirus disease 2019 in Wuhan, China, JAMA neurology, 77 (2020) 683-690.

16. Poyiadji N, Shahin G, Noujaim D, Stone M, Patel S, Griffith B. COVID-19-associated acute hemorrhagic necrotizing encephalopathy: CT and MRI features. Images Radiol, in; 2020.

17. Rubinstein SM, Warner JL. COVID-19 and haematological malignancy: navigating a narrow strait. The Lancet Haematology. 2020;7:e701-3.

18. Speth C, Löffler J, Krappmann S, Lass-Flörl C, Rambach G. Platelets as immune cells in infectious diseases. Future microbiology. 2013;8:1431-51.

19. Taha M, Sharma A, Soubani A. Clinical deterioration during neutropenia recovery after G-CSF therapy in patient with COVID-19, Respiratory medicine case reports, 31 (2020) 101231.

20. Vijenthira A, Gong IY, Fox TA, Booth S, Cook G, Fattizzo B, Martín-Moro F, Razanamahery J, Riches JC, Zwicker J. Outcomes of patients with hematologic malignancies and COVID-19: a systematic review and meta-analysis of 3377 patients, Blood. The Journal of the American Society of Hematology. 2020;136:2881-92.

21. Wang D, Hu B, Hu C, Zhu F, Liu X, Zhang J, Wang B, Xiang H, Cheng Z, Xiong Y. Clinical characteristics of 138 hospitalized patients with 2019 novel coronavirus-infected pneumonia in Wuhan. China Jama. 2020;323:1061-9.

22. Wang H, Zhang L. Risk of COVID-19 for patients with cancer. Lancet Oncol. 2020;21:e181-1.

23. WHO. Report of the WHO-China joint mission on coronavirus disease 2019 (COVID-19), in, Geneva, 2020.

24. Wu Y, Xu X, Chen Z, Duan J, Hashimoto K, Yang L, Liu C, Yang C, Nervous system involvement after infection with COVID-19 and other coronaviruses, Brain, behavior, and immunity, (2020).

25. Yeoh CB, Lee KJ, Rieth EF, Mapes R, Tchoudovskaia AV, Fischer GW, Tollinche LE. COVID-19 in the Cancer Patient. Anesth Analg. 2020;131:16-23.

26. Yu J, Ouyang W, Chua ML, Xie C, SARS-CoV-2 transmission in patients with cancer at a tertiary care hospital in Wuhan, China, JAMA oncology, (2020). 
27. Zhang L, Zhu F, Xie L, Wang C, Wang J, Chen R, Jia P, Guan H, Peng L, Chen Y. Clinical characteristics of COVID-19infected cancer patients: a retrospective case study in three hospitals within Wuhan. China, Annals of Oncology; 2020.

\section{Tables}

Table 1

Frequency of all cancer subtypes according to their categories

\begin{tabular}{|c|c|c|c|c|}
\hline Cancer Categories & Cancer Subtypes & Frequency & Valid Percent & Total \\
\hline \multirow[t]{15}{*}{ Solid Cancer } & Brain & 1 & 1.7 & \multirow[t]{15}{*}{41} \\
\hline & Breast & 10 & 16.7 & \\
\hline & Cholangiocarcinoma & 2 & 3.3 & \\
\hline & Colon & 9 & 15.0 & \\
\hline & Esophageal & 1 & 1.7 & \\
\hline & Gastric & 4 & 6.7 & \\
\hline & Germ T cell & 1 & 1.7 & \\
\hline & Larynx & 1 & 1.7 & \\
\hline & Lung & 3 & 5.0 & \\
\hline & MUO & 1 & 1.7 & \\
\hline & Ovary & 3 & 5.0 & \\
\hline & Pancreas & 2 & 3.3 & \\
\hline & Pancreatobiliary & 1 & 1.7 & \\
\hline & Prostate & 1 & 1.7 & \\
\hline & SCC & 1 & 1.7 & \\
\hline \multirow[t]{5}{*}{ Hematological Cancer } & Lymphoma & 6 & 10.0 & \multirow[t]{5}{*}{19} \\
\hline & Acute leukemia ${ }^{1}$ & 4 & 6.7 & \\
\hline & CLL & 6 & 10.0 & \\
\hline & Myeloma & 1 & 1.7 & \\
\hline & Hodchkine & 2 & 3.3 & \\
\hline \multicolumn{2}{|l|}{ Total } & 60 & 100.0 & 60 \\
\hline \multicolumn{5}{|c|}{${ }^{1}$ Acute lymphocytic leukemia; Acute myeloid leukemia; Acute Promyelocytic leukemia, } \\
\hline
\end{tabular}


Table 2

Frequency of symptoms of COVID-19 according to cancer category

\begin{tabular}{|c|c|c|c|c|c|}
\hline \multirow[t]{2}{*}{ Symptoms } & & \multicolumn{2}{|c|}{ Cancer Category } & \multirow{2}{*}{$\begin{array}{l}\text { Total Frequency } \\
(\%)\end{array}$} & \multirow{2}{*}{$\begin{array}{l}\text { P- } \\
\text { Value }\end{array}$} \\
\hline & & $\begin{array}{l}\text { Solid } \\
\text { Frequency } \\
(\%)\end{array}$ & $\begin{array}{l}\text { Hematologic Frequency } \\
(\%)\end{array}$ & & \\
\hline \multirow[t]{2}{*}{ Fever } & No & $14(34.1 \%)$ & $4(21.1 \%)$ & $18(30.0 \%)$ & \multirow[t]{2}{*}{0.307} \\
\hline & Yes & $27(65.9 \%)$ & $15(78.9 \%)$ & $42(70.0 \%)$ & \\
\hline \multirow[t]{2}{*}{ Dry Cough } & No & $14(34.1 \%)$ & $2(10.5 \%)$ & $16(26.7 \%)$ & \multirow[t]{2}{*}{0.056} \\
\hline & Yes & $27(65.9 \%)$ & $17(89.5 \%)$ & $44(73.3 \%)$ & \\
\hline \multirow[t]{2}{*}{ Tiredness } & No & $12(29.3 \%)$ & $5(26.3 \%)$ & $17(28.3 \%)$ & \multirow[t]{2}{*}{0.815} \\
\hline & Yes & $29(70.7 \%)$ & $14(73.7 \%)$ & $43(71.7 \%)$ & \\
\hline \multirow[t]{2}{*}{ Pain and ache } & No & $18(43.9 \%)$ & $9(47.4 \%$ & $27(45.0 \%)$ & \multirow[t]{2}{*}{0.803} \\
\hline & Yes & $23(56.1 \%)$ & $10(52.6 \%)$ & $33(55.0 \%)$ & \\
\hline \multirow[t]{2}{*}{ Sore Throat } & No & $20(48.8 \%)$ & $13(68.4 \%)$ & $33(55.0 \%)$ & \multirow[t]{2}{*}{0.158} \\
\hline & Yes & $21(51.2 \%)$ & $6(31.6 \%)$ & $27(45.0 \%)$ & \\
\hline \multirow[t]{2}{*}{ Diarrhea } & No & $36(87.8 \%)$ & $15(78.9 \%)$ & $51(85.0 \%)$ & \multirow[t]{2}{*}{0.175} \\
\hline & Yes & $5(12.2 \%)$ & $4(21.1 \%)$ & $9(15.0 \%)$ & \\
\hline \multirow[t]{2}{*}{ Conjunctivitis } & No & $40(97.6 \%)$ & $19(100.0 \%)$ & $59(98.3 \%)$ & \multirow[t]{2}{*}{0.496} \\
\hline & Yes & $1(2.4 \%)$ & $0(0.0 \%)$ & $1(1.7 \%)$ & \\
\hline \multirow[t]{2}{*}{ Headache } & No & $16(39.0 \%)$ & $11(57.9 \%)$ & $27(45.0 \%)$ & \multirow[t]{2}{*}{0.175} \\
\hline & Yes & $25(61.0 \%)$ & $8(42.1 \%)$ & $33(55.0 \%)$ & \\
\hline \multirow[t]{2}{*}{ Ageusia (loss of taste) } & No & $36(87.8 \%)$ & $16(84.2 \%)$ & $52(86.7 \%)$ & \multirow[t]{2}{*}{0.706} \\
\hline & Yes & $5(12.2 \%)$ & $3(15.8 \%)$ & $8(13.3 \%)$ & \\
\hline \multirow[t]{2}{*}{ Anosmia (loss of smell) } & No & $33(80.5 \%)$ & $17(89.5 \%)$ & $50(83.3 \%)$ & \multirow[t]{2}{*}{0.389} \\
\hline & Yes & $8(19.5 \%)$ & $2(10.5 \%)$ & $10(16.7 \%)$ & \\
\hline \multirow[t]{2}{*}{ Difficulty Breathing } & No & $23(56.1 \%)$ & $12(63.2 \%)$ & 35 (58.3\%) & \multirow[t]{2}{*}{0.609} \\
\hline & Yes & $18(43.9 \%)$ & $7(36.8 \%)$ & $25(41.7 \%)$ & \\
\hline \multirow[t]{2}{*}{ Shortness Of Breath } & No & $23(56.1 \%)$ & $11(57.9 \%)$ & $34(56.7 \%)$ & \multirow[t]{2}{*}{0.897} \\
\hline & Yes & $18(43.9 \%)$ & $8(42.1 \%)$ & $26(43.3 \%)$ & \\
\hline \multirow[t]{2}{*}{ Chest pain } & No & $24(58.5 \%)$ & $13(68.4 \%)$ & $37(61.7 \%)$ & \multirow[t]{2}{*}{0.468} \\
\hline & Yes & $17(41.5 \%)$ & $6(31.6 \%)$ & $23(38.3 \%)$ & \\
\hline \multirow{2}{*}{$\begin{array}{l}\text { Dysarthria (difficulty } \\
\text { speaking) }\end{array}$} & No & $30(73.2 \%)$ & $19(100.0 \%)$ & $49(81.7 \%)$ & $0.009 *$ \\
\hline & Yes & $11(26.8) \%$ & $0(0.0 \%)$ & $11(18.3 \%)$ & \\
\hline Frailty & No & $18(43.9 \%)$ & $14(73.7 \%)$ & $32(53.3 \%)$ & $0.029 *$ \\
\hline
\end{tabular}




\begin{tabular}{|llllll|}
\hline \multirow{2}{*}{ Exhaustion } & Yes & $23(56.1 \%)$ & $5(26.3 \%)$ & $28(46.7 \%)$ & \\
& No & $10(24.4 \%)$ & $4(21.1 \%)$ & $14(23.3 \%)$ & 0.778 \\
\cline { 2 - 5 } Confusion and Bewilderment & $31(75.6 \%)$ & $15(78.9 \%)$ & $46(76.7 \%)$ & \\
\cline { 2 - 5 } & Yo & $40(97.6 \%)$ & $19(100.0 \%)$ & $59(98.3 \%)$ & 0.380 \\
\cline { 2 - 5 } & Yes & $1(2.4 \%)$ & $0(0.0 \%)$ & $1(1.7 \%)$ & \\
\hline
\end{tabular}

Table 3

hematological results in COVID-19 cancer patients

\begin{tabular}{|c|c|c|c|c|c|}
\hline Variable & Cancer Category & $\mathbf{N}$ & Mean & SD & P-value \\
\hline \multirow[t]{2}{*}{ SO2 (\%) before oxygen therapy } & Solid & 41 & 88.00 & 6.611 & \multirow[t]{2}{*}{0.610} \\
\hline & Hematologic & 19 & 88.00 & 5.981 & \\
\hline \multirow[t]{2}{*}{ SO2 (\%) after oxygen therapy } & Solid & 21 & 89.29 & 4.745 & \multirow[t]{2}{*}{0.858} \\
\hline & Hematologic & 11 & 89.36 & 4.905 & \\
\hline \multirow[t]{2}{*}{ WBC $* 1000 / \mathrm{mm}^{3}$} & Solid & 39 & 14702.82 & 24718.347 & \multirow[t]{2}{*}{0.233} \\
\hline & Hematologic & 19 & 31367.37 & 33432.286 & \\
\hline \multirow[t]{2}{*}{$\mathrm{Hb} \mathrm{g} / \mathrm{dL}$} & Solid & 41 & 10.76 & 1.150 & \multirow[t]{2}{*}{0.167} \\
\hline & Hematologic & 19 & 10.13 & 1.558 & \\
\hline \multirow[t]{2}{*}{ Plt } & Solid & 41 & 140227.95 & 57046.119 & \multirow[t]{2}{*}{0.044} \\
\hline & Hematologic & 19 & 109315.79 & 68220.274 & \\
\hline
\end{tabular}


Table 4

The basis of chemotherapy for cancer patients during the Covid-19 pandemic

\begin{tabular}{|c|c|}
\hline Cancer types & Chemotherapy \\
\hline Brain & Temo/PCV \\
\hline Breast & Gem/Nav, FAC, Herceptin, TEC \\
\hline Cholangiocarcinoma & Gem/Cis/5FU \\
\hline Colon & Folfox/Ave, Folfiri/ERB, Pemberzolimab, Oxall/capa \\
\hline Esophageal & Tax/Cis/5fu \\
\hline Gastric & Folfiri/Herceptin, Tax/Cis/5fu \\
\hline Larynx & Tax/Cis/5fu \\
\hline Lung & Gem/Cis, Etopos/Cis, Taol/Car \\
\hline Metastatic of Unknown Origin & Gem/Cis/5fu \\
\hline ovary & Carbo/cam/Av, Tax/Carb/Av, BEP \\
\hline Pancreas & Gem/Cis/5fu \\
\hline Pancreatobilliary & Gem/Cis/5fu \\
\hline Prostate & Taxoter/BIC \\
\hline Squamous cell carcinoma & Tax/Cis/5fu \\
\hline Germ cell Tumor & TAX/Cis \\
\hline Acute lymphocytic leukemia & Hyper VAD \\
\hline Acute myeloid leukemia & FLANG \\
\hline Acute Promyelocytic leukemia & ATRA/Chem, Arsenic \\
\hline Hodchkine & ABVD \\
\hline Lymphoma & Rituximab, R-CVP, Flu/Cyc/R, Hyper CVAD \\
\hline Chronic lymphocytic leukemia & Chlora/PRD \\
\hline Multiple myeloma & Velcade \\
\hline \multicolumn{2}{|c|}{$\begin{array}{l}\text { Temo: Temozolomide; PCV: Procarbazine, Lomustine (CCNU), and Vincristine; Gem: Gemcitabin; Nav: Vinorelbine; } \\
\text { FAC: Fluorouracil, Adriamycin and Cytoxan; TEC: Docetaxel/Epirubicin/Cyclophosphamide; Cis: Cisplatin; Folfox: } \\
\text { Leucovorin, 5FU, Oxaliplatin; Folinic Acid (Leucovorin, Calcium Folinate Or FA); 5FU: Fluorouracil; Cap: Capecitabine } \\
\text { (Xeloda); Tax: Paclitaxel; VP: Etoposide; ABVD: Adriamycin, Bleomycin, Vinblastin Dacarbazin; Etop: Etoposid; Hyper- } \\
\text { CVAD :Hyperfractionated Cyclophosphamide, Vincristine, Doxorubicin, and Prednisolone; RCVP: Rituximab, } \\
\text { Cyclophosphamide, Vincristine Sulfate, and Prednisone; PRD: Prednisolone; FLANG: Fludarabine, Cytosine } \\
\text { Arabinoside, Mitoxantrone, and G-CSF;BEP: Bleomycin, Etoposide, and Cisplatin; P: Cisplatin, MIC: Mitomycin, } \\
\text { Ifosfamide, Cisplatin, Carbo: Carboplatin }\end{array}$} \\
\hline
\end{tabular}


Table 5

Frequency of COVID-19 symptoms according to cancer category in deceased patients

\begin{tabular}{|c|c|c|c|c|c|c|c|}
\hline Tumor & Solid & & & & Hematolog & & \\
\hline Sex & Male & Male & Female & Female & Male & Male & Female \\
\hline Age & 55 & 68 & 58 & 38 & 66 & 65 & 32 \\
\hline $\begin{array}{l}\text { Type Of } \\
\text { Cancer }\end{array}$ & Brain & Lung & Cholangicarcinoma & Lung & ALL & MM & AML \\
\hline Stage & & IV & IV & IV & Refractory & - & Refractory \\
\hline Fever & Yes & Yes & Yes & Yes & Yes & No & Yes \\
\hline Tiredness & Yes & Yes & Yes & No & No & No & Yes \\
\hline Pain & Yes & No & Yes & No & No & No & No \\
\hline Sore Throat & Yes & No & Yes & No & No & No & No \\
\hline Diarrhea & No & Yes & No & No & Yes & Yes & Yes \\
\hline Headache & Yes & Yes & Yes & No & Yes & Yes & No \\
\hline $\begin{array}{l}\text { Ageusia } \\
\text { (Loss Of } \\
\text { Taste) }\end{array}$ & Yes & No & Yes & No & No & No & No \\
\hline $\begin{array}{l}\text { Anosmia } \\
\text { (Loss Of } \\
\text { Smell) }\end{array}$ & Yes & No & No & No & No & No & No \\
\hline $\begin{array}{l}\text { Difficulty } \\
\text { Breathing }\end{array}$ & Yes & Yes & Yes & Yes & Yes & Yes & No \\
\hline $\begin{array}{l}\text { Shortness } \\
\text { Of Breath }\end{array}$ & Yes & Yes & Yes & Yes & Yes & Yes & No \\
\hline Chest Pain & Yes & Yes & Yes & Yes & No & Yes & No \\
\hline $\begin{array}{l}\text { Dysarthria } \\
\text { (Difficulty } \\
\text { Speaking) }\end{array}$ & Yes & No & Yes & Yes & No & No & No \\
\hline Frailty & Yes & Yes & Yes & Yes & No & No & No \\
\hline Exhaustion & Yes & No & Yes & Yes & Yes & Yes & No \\
\hline $\begin{array}{l}\mathrm{SO} 2 \% \\
\text { before } 02 \\
\text { therapy }\end{array}$ & 79 & 76 & 78 & 76 & 76 & 76 & 92 \\
\hline $\begin{array}{l}\text { S02 \% after } \\
\text { O2 therapy }\end{array}$ & 82 & 82 & 85 & 81 & 80 & 83 & - \\
\hline $\begin{array}{l}\text { WBC } \\
\star 1000 / \mathrm{Mm}^{3}\end{array}$ & 3500 & 3500 & 3200 & 21000 & 1200 & 2200 & 800 \\
\hline $\mathrm{Hb}$ G/DI & 10.4 & 11 & 8.9 & 11 & 7 & 8 & 8 \\
\hline
\end{tabular}

SO2: saturated oxygen; WBC: White Blood Cells; Hb: Hemoglobin; Plt: Platelet; ALL: Acute lymphocytic leukemia; AML: Acute myeloid leukemia; MM: Multiple Myeloma 


\begin{tabular}{|llllllll|}
\hline $\begin{array}{l}\text { Tumor } \\
\text { Category }\end{array}$ & Solid & & & & Hematologic & \\
\hline Plt & 90000 & 120000 & 58000 & 80000 & 20000 & 65000 & 12000 \\
\hline $\begin{array}{l}\text { Treatment } \\
\text { Option }\end{array}$ & Recigen & $\begin{array}{l}\text { Hydroxy- } \\
\text { chloroquine }\end{array}$ & $\begin{array}{l}\text { Recigen, } \\
\text { \& Remdesivir, } \\
\text { Corticosteroid }\end{array}$ & Recigen & $\begin{array}{l}\text { Hydroxy- } \\
\text { chloroquine }\end{array}$ & $\begin{array}{l}\text { Hydroxy- } \\
\text { chloroquine } \\
\text { \& Recigen }\end{array}$ & Recigen \\
\hline $\begin{array}{l}\text { Pulmonary } \\
\text { Involvement }\end{array}$ & Bilateral & Bilateral & Bilateral & Bilateral & Bilateral & Bilateral & No \\
\hline $\begin{array}{l}\text { Plural } \\
\text { Involvement }\end{array}$ & No & Yes & Yes & Yes & No & No & No \\
\hline
\end{tabular}

SO2: saturated oxygen; WBC: White Blood Cells; Hb: Hemoglobin; Plt: Platelet; ALL: Acute lymphocytic leukemia; AML: Acute myeloid leukemia; MM: Multiple Myeloma 